\title{
A New Identification Method for Bolt Looseness in Wind Turbine Towers
}

\author{
He Xianlong (iD and She Tianli \\ Key Laboratory of Earthquake Engineering and Engineering Vibration, Institute of Engineering Mechanics, \\ China Earthquake Administration, Harbin 150080, China \\ Correspondence should be addressed to He Xianlong; 524245186@qq.com
}

Received 8 April 2019; Accepted 20 June 2019; Published 7 July 2019

Guest Editor: Franco Concli

Copyright (c) 2019 He Xianlong and She Tianli. This is an open access article distributed under the Creative Commons Attribution License, which permits unrestricted use, distribution, and reproduction in any medium, provided the original work is properly cited.

\begin{abstract}
Flange plates are key joining components used in wind turbine towers. Bolt looseness results in common fatigue damage in wind turbine towers. Detailed vibration tests were carried out on six wind turbine towers with loose bolts. First, the bolt looseness situation of each wind turbine tower was detected by the torque method. The vibration characteristics of each tower were then tested and analyzed in detail before maintenance. Finally, the vibration characteristics were tested and analyzed in detail after maintenance. The experimental data analysis shows that the first-order natural frequencies of the wind turbine towers before and after bolt maintenance do not change; the damping ratio does not change significantly; and the first-order vibration mode remains effectively unchanged. The phase difference between the upper and the lower plates of a flange has a significant and abrupt characteristic even when the bolt looseness ratio is 6\%; however, the phase difference does not exhibit this characteristic after the flange bolts are retightened. The experimental results show that compared with other vibration characteristics, the first-order phase difference characteristic of wind turbine towers is more markedly affected by the looseness of the flange bolts; hence, this characteristic can be used as a diagnostic that reflects flange bolt looseness. Whether the flange bolts of a given tower require tightening can be identified based on whether the absolute value of the phase difference between the upper and lower plates of the flanges suddenly increases. This research result can provide a new method for the identification of bolt looseness in wind turbine towers.
\end{abstract}

\section{Introduction}

In recent years, collapse accidents of wind turbine towers in China have become common. For example, in 2008, a wind turbine tower at a wind farm in Jilin Province collapsed completely after only three years of use [1-4]. In 2010, a wind turbine tower at a wind farm was blown down by wind because the flange bolts were not fastened in time $[2,5,6]$. In 2014, a wind turbine tower in Gansu Province suddenly collapsed after less than one year of service $[7,8]$.

Through analyses of the above collapse accidents, it can be concluded that the flange bolt looseness of wind turbine towers is the main factor causing their collapse. It is also one of the most common deficiencies in wind turbine towers. The main factors causing the looseness of flange bolt are as follows [7-14]:
(1) There are one or more errors in the proper installation of the main operating components of wind turbines, which generate large vibrations as the wind turbine is in operation, which ultimately results in nut looseness of flange bolts.

(2) The bolts in the flanges are not properly tightened in place, which causes the nuts to loosen gradually under the action of vibration.

(3) The material properties of bolts are unsatisfactory. Under long-term wind-induced vibrations, the diameters of the bolts are gradually tapered, resulting in nut looseness.

Therefore, it is helpful to prevent the collapse of wind turbine towers by finding bolt looseness as early as possible. 
Existing methods mainly center on manually checking bolts one-by-one by using the torque method to identify loose bolts [1, 15-17]. Although this method checks bolt looseness in detail, it is time consuming and laborious to perform because the number of bolts in each wind turbine tower is close to a hundred. Therefore, studies on the rapid identification of flange bolt looseness of wind turbine towers have great engineering value, which are beneficial to the reduction of maintenance costs and towards the development of safety monitoring technology for wind turbine tower operation [18-21].

Wind turbine towers are usually made up of multisection towers. Each tower section has flanges at its bottom and top. The flanges of adjacent towers are connected by a large number of high-performance bolts. If a wind turbine tower is undamaged, its structural dynamic response functiontransfer function and other linear vibration states are theoretically fixed. However, when a flange bolt is loose, the situation is equivalent to a stiffness reduction of the bolted joint [16], which results in a change of the interaction force between adjacent towers that may change the transfer function between adjacent towers and change the transfer function of the entire wind turbine tower. Therefore, theoretically, if the bolt looseness ratio of the wind turbine tower reaches a certain level, the vibration characteristics of the wind turbine tower will change $[8,22]$.

Structural vibration modal parameters are important physical parameters of structural transfer functions, which mainly include their natural frequency, vibration mode, damping ratio, phase difference, stiffness, and mass $[12,13,23]$. Structural damage, such as loose bolts in wind turbine towers, can be recognized based on tests and calculations of the dynamic response transfer function of a given wind turbine tower. Analyses of structural vibration modal parameters of in-service wind turbine towers are important, especially when determining the dynamic response transfer function of the bolted joint members between adjacent towers.

In this paper, six wind turbine towers that suffer from bolt looseness in a wind farm have been tested in detail before and after the bolts are retightened. It can be seen from the measured spectra that the vibration energy of a wind turbine tower is mainly concentrated around the first-order natural frequency point, while the spectral characteristics of other frequency points are not very prominent. Therefore, in this paper, we focus on the change of the first-order modal parameters before and after tower maintenance. This approach allows one to obtain a detailed understanding of the first-order natural frequency and any change in the corresponding damping ratio before and after maintenance. Meanwhile, the vibration signal of a measuring point in the direction of the wind (the bottom measuring point of the tower) is used as the vibration input signal of the wind turbine tower. A normalized curve of the amplitude-frequency response and a curve of the phase-frequency response of other measuring points in the downwind direction relative to the first measuring point are, respectively, made. The first-order mode curve that corresponds to the firstorder natural frequency is then obtained based on the normalized curve of the amplitude-frequency response of each measuring point. The phase-frequency amplitude that corresponds to the first-order natural frequency is determined based on the phase-frequency response curve. Furthermore, the phase differences of the other measuring points relative to the first measuring point at the first-order natural frequency point are obtained. Finally, the elevation layout of each measuring point is taken as the $x$-axis, where the vibration mode and the phase difference curve that corresponds to the first-order natural frequency point of the wind turbine tower are drawn. Through a data analysis, the first-order natural frequencies of the six wind turbine towers and their changing damping ratios are determined; vibration mode curves and the phase difference curves corresponding to the first-order natural frequencies before and after bolt tightening are also calculated. It is concluded that the phase difference curve that corresponds to the first-order natural frequency is sensitive to flange bolt looseness.

\section{Vibration Test of Wind Turbine Towers}

The considered onshore wind farm is located in Gansu Province. A large number of wind turbine towers at the farm have loose flange bolts, where some bolt looseness ratios exceed $50 \%$. At this farm, a wind turbine tower collapsed after less than one year of service because loose bolts were not found in time. When a bolt (nut) is tightened by the torque method or the rotation angle method and the assembly torque of the tightening bolt (nut) reaches an upper limit, the bolt is considered as being "tightly secured." In this definition, the upper limit of the torque is determined according to the combined strength of the bolt and the nut, which is usually taken as $70 \%$ of the torque that corresponds to the yield strength. The bolt (nut) is thus secure when it can no longer be displaced (or further rotated).

Bolt looseness means that when a bolt (nut) is tightened by the torque or rotation angle method and the assembly torque of the tightening bolt (nut) is lower than the upper limit, the bolt (nut) can still be further displaced (or rotated) [14]. Therefore, it is possible to detect whether a bolt (nut) is loose by the torque or rotation angle method and quantify the bolt (nut) looseness degree based on the initial tightening torque value. In this test, only the number of loose bolts (nuts) was recorded, where the initial tightening torque value was not recorded due to the imperfect experimental plan and the large amount of fieldwork when retightening the bolts (nuts).

Vibration is one of the main factors that cause bolt looseness. In turn, loose bolts can cause changes in the vibration characteristics of their host wind turbine tower. Therefore, six wind turbine towers with different bolt looseness degrees were selected for detailed vibration measurements. The effect of bolt looseness on the vibration characteristics of each wind turbine tower was studied. The basic properties of the six wind turbine towers and their bolt looseness ratios are shown in Table 1. The No. 1 and No. 2 wind turbine towers are $1.5 \mathrm{MW}$ units, while the No. 3 to No. 6 wind turbine towers are $2 \mathrm{MW}$ units. The bolt specifications of the tower flanges are M36* 480, 10.9 grade 
TABLE 1: The bolt looseness ratio statistics of the six wind turbine towers.

\begin{tabular}{lccc}
\hline Tower ID & $\begin{array}{c}\text { Theoretical design value of the first-order } \\
\text { natural frequency }(\mathrm{Hz})\end{array}$ & $\begin{array}{c}\text { The looseness ratio of three flange plates } \\
\text { from the bottom up }\end{array}$ & Notes \\
\hline 1 & 0.380 & $28 \% ; 7 \% ; 12 \%$ & Height $75 \mathrm{~m}$, four section towers \\
2 & 0.380 & $15 \% ; 14 \% ; 8 \%$ & Height $75 \mathrm{~m}$, four section towers \\
3 & 0.311 & $10 \% ; 8 \% ; 6 \%$ & Height $80 \mathrm{~m}$, four section towers \\
4 & 0.311 & $32 \% ; 18 \% ; 9 \%$ & Height $80 \mathrm{~m}$, four section towers \\
5 & 0.311 & $64 \% ; 24 \% ; 15 \%$ & Height $80 \mathrm{~m}$, four section towers \\
6 & 0.311 & $34 \% ; 17 \% ; 6 \%$ & Height $80 \mathrm{~m}$, four section towers \\
\hline
\end{tabular}

Note. The bolt looseness ratio refers to the percentage of loose bolts (nuts) between the upper and lower flanges divided by the total number of flange bolts (nuts).

high-strength bolts, and their characteristic test results are in accordance with GB/T3098.1-2010 "Mechanical performance bolts, screws, and studs for fasteners."

Twelve measuring points were arranged on the wall of each wind turbine tower from bottom to top. Each measuring point was arranged with a QZ2013 single-component force balance accelerometer produced by Beijing Tengsheng Qiaokang Technology Co., Ltd., along the main wind direction (the northwest direction). The layout is described in Table 2. The accelerometer has a frequency range of 0 to $200 \mathrm{~Hz}$, and it has good pickup capability of microvibrations and strong vibrations. A 24 bit G01NET-2 synchronous dynamic data acquisition instrument, produced by Beijing Tengsheng Qiaokang Technology Co., Ltd., was used for data acquisition.

In order to study the sensitivity of the vibration characteristics of each wind turbine towers to its corresponding flange looseness degree, tests were carried out as shown in Table 3. The sampling frequency was uniform $64 \mathrm{~Hz}$ during the test, and the data were continuously recorded for $20 \mathrm{~min}$ under each working condition. Typical measured waveforms of wind turbine tower vibrations are shown in Figures 1 and 2.

\section{Analysis of the Vibration Characteristics of Wind Turbine Towers}

3.1. Analysis of the Natural Frequency and Damping Ratio. An FFT average spectrum analysis (average window of $81920 \times 64$ and a frequency resolution of $0.00078 \mathrm{~Hz}$ ) was carried out on the vibration data collected under various working conditions, where the natural frequency of each wind turbine tower was obtained. The damping ratio at the inherent frequency point was calculated based on the half power spectrum refinement method, where example power spectra are shown in Figure 3. It can be seen from the power spectra that the vibration energy of the wind turbine tower is mainly concentrated at the first-order natural frequency point, while the other natural frequencies are not prominent. Tables 4 and 5 show the first-order natural frequencies and damping ratios of each wind turbine tower.

It can be seen from Figure 3 that the main vibration energy of the wind turbine tower is concentrated at the first-order natural frequency point of the tower, and other natural frequency points are not prominent.
Therefore, the main vibration of wind turbine towers is of ultralow frequency, which indicates that a wind turbine tower can be considered as a very flexible high-rise building.

It can be seen from Table 4 that the natural frequency of the first-order vibration of each wind turbine tower is exactly the same before and after the flange plates were tightened. Moreover, the first-order natural frequencies measured under inactive and active conditions are also the same. This shows that although the bolt looseness ratios of the flanges were relatively high (for example, the bolt looseness ratio of the first flange of the No. 5 wind turbine tower was as high as 64\%), the first-order natural frequencies after the bolts were retightened were still exactly the same as those before tightening. Therefore, by analyzing the vibrational energy of the six wind turbine towers, although the vibration energy of the surface tower is mainly concentrated at the first-order natural frequency, the firstorder natural frequency is not sensitive to bolt looseness in the wind turbine flanges.

It can be seen from Table 5 that the damping ratio corresponding to the first-order natural frequency of each wind turbine tower changed very little before and after the bolts were tightened, where the damping ratios of the No. $1,2,3,4$, and 6 wind turbine towers were less than $3 \%$. Although the bolt looseness ratio of the first flange of the No. 5 wind turbine tower reached $63 \%$, its damping ratio only changed by about $10 \%$. Therefore, according to the vibration test of the six wind turbine towers, the damping ratios corresponding to the first-order natural frequencies of the surface towers were not very sensitive to the bolt looseness of the wind turbine flanges.

3.2. Analysis of First-Order Vibration Mode and Phase Difference of the Wind Turbine Towers. Assuming a certain order natural frequency value of the structure is $f$, the vibration acceleration function of the different positions at this frequency point is assumed to be

$$
a(t, h)=A_{h} \sin \left(2 \pi f t+\theta_{h}\right)
$$

where $h$ is the position, $A_{h}$ is the acceleration amplitude, and $\theta_{h}$ is the initial phase. If $h$ is quantized, the vibration function group of each position at this frequency point can be obtained as 
TABLE 2: Description of the horizontal vibration measuring points in the prevailing wind direction of each wind turbine tower.

\begin{tabular}{|c|c|c|c|}
\hline $\begin{array}{l}\text { Measuring } \\
\text { point ID }\end{array}$ & Arrangement position & $\begin{array}{l}\text { Point elevation of the No. } 1 \text { and No. } 2 \\
\text { wind turbine towers (m) }\end{array}$ & $\begin{array}{l}\text { Point elevation of the No. } 3 \text { to No. } 6 \\
\text { wind turbine towers (m) }\end{array}$ \\
\hline 1 & Bottom of the wind turbine tower & 0 & 0 \\
\hline 2 & Middle of the first section & 6 & 8 \\
\hline 3 & $\begin{array}{l}\text { Top of the first section (bottom of the } \\
\text { first flange plate) }\end{array}$ & 12 & 16 \\
\hline 4 & $\begin{array}{l}\text { Bottom of the second section (top of the } \\
\text { first flange plate) }\end{array}$ & 13 & 17 \\
\hline 5 & Middle of the second section & 26 & 28 \\
\hline 6 & $\begin{array}{l}\text { Top of the second section (bottom of } \\
\text { the second flange plate) }\end{array}$ & 40 & 40 \\
\hline 7 & $\begin{array}{l}\text { Bottom of the third section (top of the } \\
\text { second flange plate) }\end{array}$ & 41 & 41 \\
\hline 8 & Middle of the third section. & 49 & 50 \\
\hline 9 & $\begin{array}{c}\text { Top of the third section (bottom of the } \\
\text { third flange plate) }\end{array}$ & 58 & 60 \\
\hline 10 & $\begin{array}{l}\text { Bottom of the fourth section (top of the } \\
\text { third flange plate) }\end{array}$ & 59 & 61 \\
\hline 11 & Middle of the fourth section & 66.5 & 70 \\
\hline 12 & Top of the fourth section & 75 & 80 \\
\hline
\end{tabular}

TABLE 3: Vibration test conditions of the wind turbine towers.

\begin{tabular}{lccc}
\hline Experiment ID & Content of working condition & Test environment condition & Tightening condition of flange plate \\
\hline 1 & Vibration test when tower is in an inactive state & Wind speed is less than $5 \mathrm{~m} / \mathrm{s}$ & Before tightening \\
2 & Vibration test when tower is in an inactive state & Wind speed is $18 \sim 2 \mathrm{~m} / \mathrm{s}$ & Before tightening \\
3 & Vibration test when tower is in an active state & Wind speed is $7 \sim 10 \mathrm{~m} / \mathrm{s}$ & Before tightening \\
4 & Vibration test when tower is in an active state & Wind speed is $18 \sim 24 \mathrm{~m} / \mathrm{s}$ & Before tightening \\
5 & Vibration test when tower is in an inactive state & Wind speed is $18 \sim 22 \mathrm{~m} / \mathrm{s}$ & After tightening \\
6 & Vibration test when tower is in an active state & Wind speed is $18 \sim 24 \mathrm{~m} / \mathrm{s}$ & After tightening \\
\hline
\end{tabular}

Note. Flange tightening refers to only retightening of each bolt on the flange by the torque method.

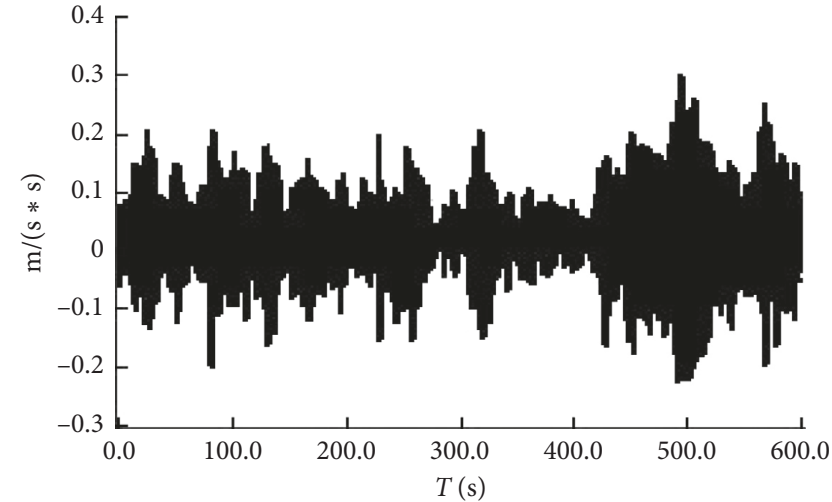

FIGURE 1: Vibration acceleration time-history curve at the top of No. 1 tower in working conditions at wind speeds of $7-10 \mathrm{~m} / \mathrm{s}$.

$$
\left\{\begin{array}{c}
a\left(t, h_{0}\right)=A_{h_{0}} \sin \left(2 \pi f t+\theta_{h_{0}}\right) \\
a\left(t, h_{1}\right)=A_{h_{1}} \sin \left(2 \pi f t+\theta_{h_{1}}\right) \\
\cdot \\
a\left(t, h_{n}\right)=A_{h_{n}} \sin \left(2 \pi f t+\theta_{h_{n}}\right)
\end{array}\right\}
$$

Then, the array $\left[A_{h_{0}}, A_{h_{1}}, \ldots, A_{h_{n}}\right]$ is the amplitude of the acceleration mode at each position of the frequency point. If

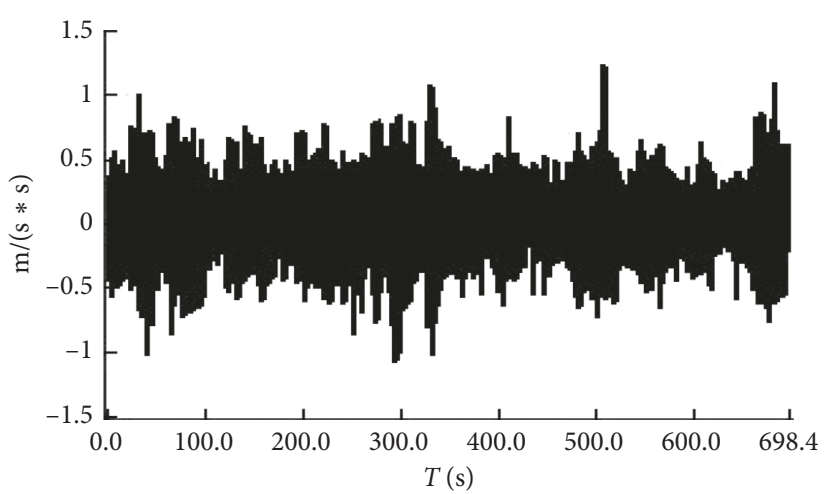

FIgURE 2: Vibration acceleration time-history curve at the top of No. 3 tower in working condition at wind speeds of $8-24 \mathrm{~m} / \mathrm{s}$.

the amplitude of the shape of the position is the reference value, the relative amplitude pattern of the frequency point is obtained as

$$
\left[0, A_{h_{1}}-A_{h_{0}}, \ldots, A_{h_{n}}-A_{h_{0}}\right]
$$

Similarly, an array of initial phase values of acceleration at each frequency point is

$$
\left[\theta_{h_{0}}, \theta_{h_{1}}, \ldots, \theta_{h_{n}}\right] \text {. }
$$

If the initial phase value $h_{0}$ of the acceleration of the position is the reference value, the relative initial phase 


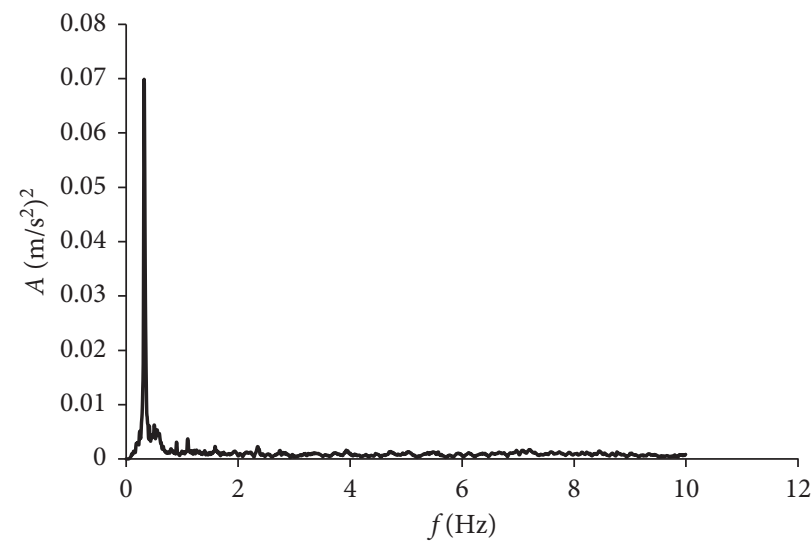

(a)

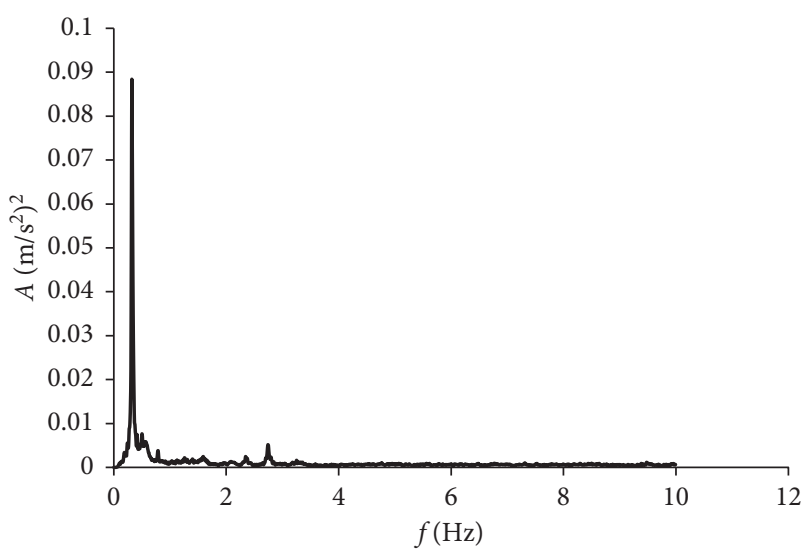

(b)

FIGURE 3: Vibration FFT spectra of two wind turbine towers (1 and 3). The spike in each subplot corresponds to the first-order natural frequency of each tower. (a) Vibration FFT spectra of No. 1 wind turbine tower. (b) Vibration FFT spectra of No. 3 wind turbine tower.

TABLE 4: Natural frequencies of the wind turbine towers.

\begin{tabular}{|c|c|c|c|c|c|c|}
\hline \multirow{2}{*}{$\begin{array}{l}\text { Tower } \\
\text { ID }\end{array}$} & \multicolumn{4}{|c|}{ Test results before tightening $(\mathrm{Hz})$} & \multicolumn{2}{|c|}{ Test results after tightening $(\mathrm{Hz})$} \\
\hline & $\begin{array}{c}\text { Working condition } \\
1\end{array}$ & $\begin{array}{c}\text { Working condition } \\
2\end{array}$ & $\begin{array}{c}\text { Working condition } \\
3\end{array}$ & $\begin{array}{c}\text { Working condition } \\
4\end{array}$ & $\begin{array}{c}\text { Working condition } \\
5\end{array}$ & $\begin{array}{c}\text { Working condition } \\
6\end{array}$ \\
\hline 1 & 0.391 & 0.391 & 0.391 & 0.391 & 0.391 & 0.391 \\
\hline 2 & 0.391 & 0.391 & 0.391 & 0.391 & 0.391 & 0.391 \\
\hline 3 & 0.322 & 0.322 & 0.322 & 0.322 & 0.322 & 0.322 \\
\hline 4 & 0.322 & 0.322 & 0.322 & 0.322 & 0.322 & 0.322 \\
\hline 5 & 0.322 & 0.322 & 0.322 & 0.322 & 0.322 & 0.322 \\
\hline 6 & 0.322 & 0.322 & 0.322 & 0.322 & 0.322 & 0.322 \\
\hline
\end{tabular}

TABLE 5: Damping ratio of the first-order natural frequency of each wind turbine tower.

\begin{tabular}{|c|c|c|c|c|c|c|}
\hline \multirow{2}{*}{$\begin{array}{l}\text { Tower } \\
\text { ID }\end{array}$} & \multicolumn{4}{|c|}{ Test results before tightening $(\mathrm{Hz})$} & \multicolumn{2}{|c|}{ Test results after tightening $(\mathrm{Hz})$} \\
\hline & $\begin{array}{c}\text { Working condition } \\
1\end{array}$ & $\begin{array}{c}\text { Working condition } \\
2\end{array}$ & $\begin{array}{c}\text { Working condition } \\
3\end{array}$ & $\begin{array}{c}\text { Working condition } \\
4\end{array}$ & $\begin{array}{l}\text { Working condition } \\
5\end{array}$ & $\begin{array}{c}\text { Working condition } \\
6\end{array}$ \\
\hline 1 & 0.0549 & 0.0552 & 0.538 & 0.0534 & 0.0542 & 0.0539 \\
\hline 2 & 0.0572 & 0.0579 & 0.0566 & 0.0560 & 0.0563 & 0.0567 \\
\hline 3 & 0.0485 & 0.0483 & 0.480 & 0.0481 & 0.0487 & 0.0490 \\
\hline 4 & 0.0427 & 0.0421 & 0.0428 & 0.0430 & 0.0433 & 0.0430 \\
\hline 5 & 0.0437 & 0.0429 & 0.0428 & 0.0423 & 0.0478 & 0.0473 \\
\hline 6 & 0.0494 & 0.0483 & 0.0492 & 0.0498 & 0.0496 & 0.0492 \\
\hline
\end{tabular}

difference array at each position of the frequency point is obtained as

$$
\left[0, \theta_{h_{1}}-\theta_{h_{0}}, \ldots, \theta_{h_{n}}-\theta_{h_{0}}\right]
$$

The first-order vibration modes and the first-order phase difference curves measured from the six wind turbine towers under various working conditions were analyzed in detail.

It can be seen from Figures 4-9 that the first-order vibration modes measured from the six wind turbine towers under various working conditions are very similar. Moreover, the comparisons of the first-order vibration modes before and after the bolts were retightened are also very similar. Therefore, we can conclude that the first-order vibration mode of the surface tower is not sensitive to the bolt looseness of the flange plates.
It can be seen from Figures 4-9 that the first-order phase difference curves of the six wind turbine towers under various working conditions vary greatly. Before the bolts were retightened, the phase difference curves measured for conditions 1 to 4 show a sudden change at the flange plate of the upper bolt. That is, although the elevation difference between the two measuring points of the lower and upper plates is only one meter, the phase differences have significantly increased or significantly reduced relative to other high-rises. Moreover, the phase differences between the measuring points near the upper and lower plates of the three flanges of the wind turbine tower show this characteristic. For example, although the loose bolt ratio of the third flange of the No. 3 wind turbine tower is only $6 \%$, there is a sudden change between the measuring points near the 


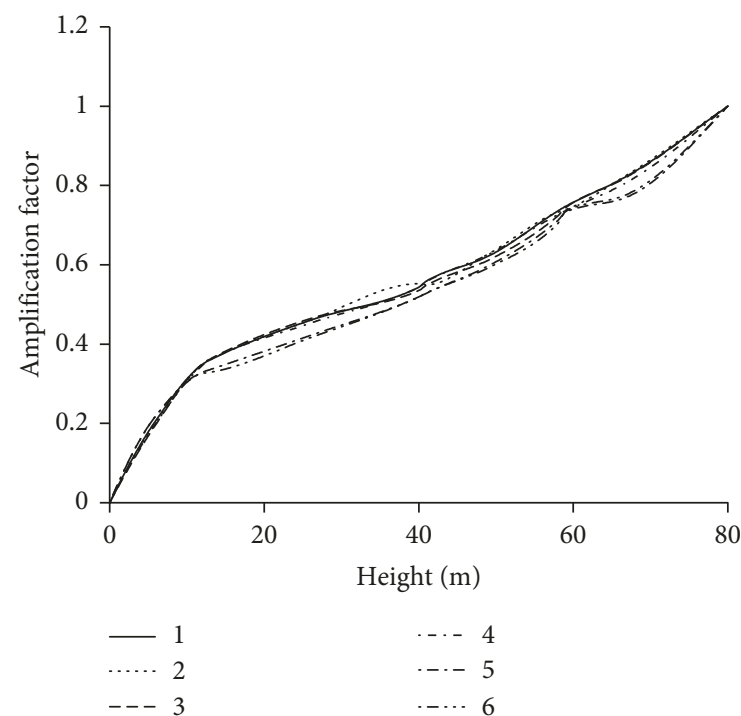

(a)

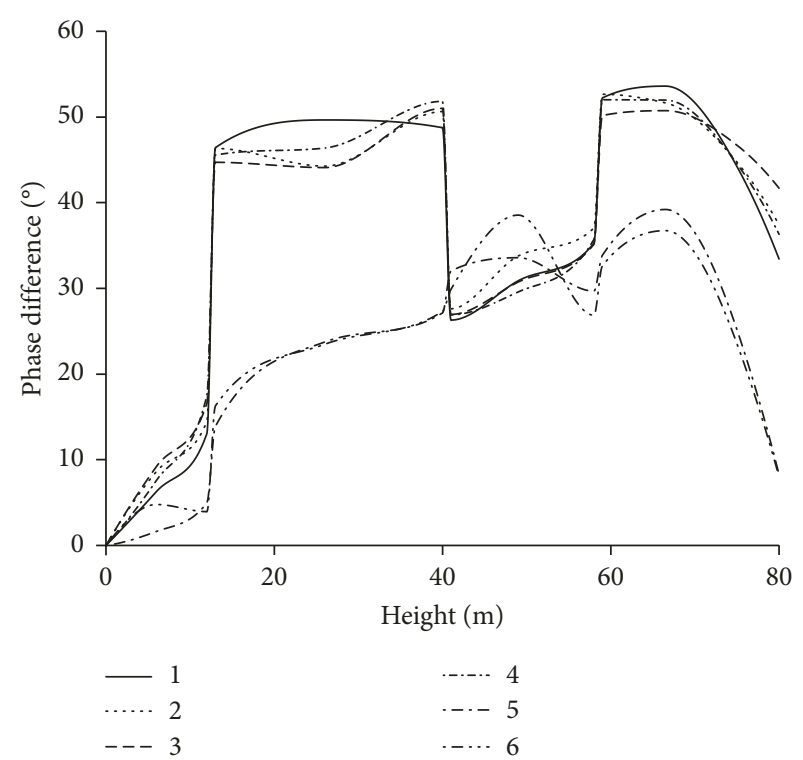

(b)

FiguRE 4: Vibration modes and phase differences of the No. 1 wind turbine tower. (a) The first-order vibration mode under six working conditions. (b) The first-order phase difference under six working conditions.

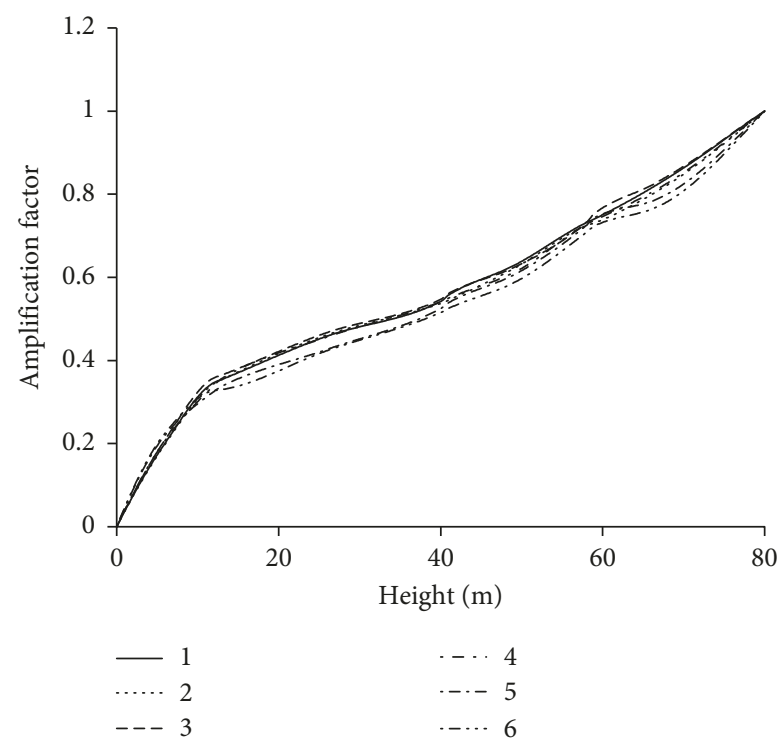

(a)

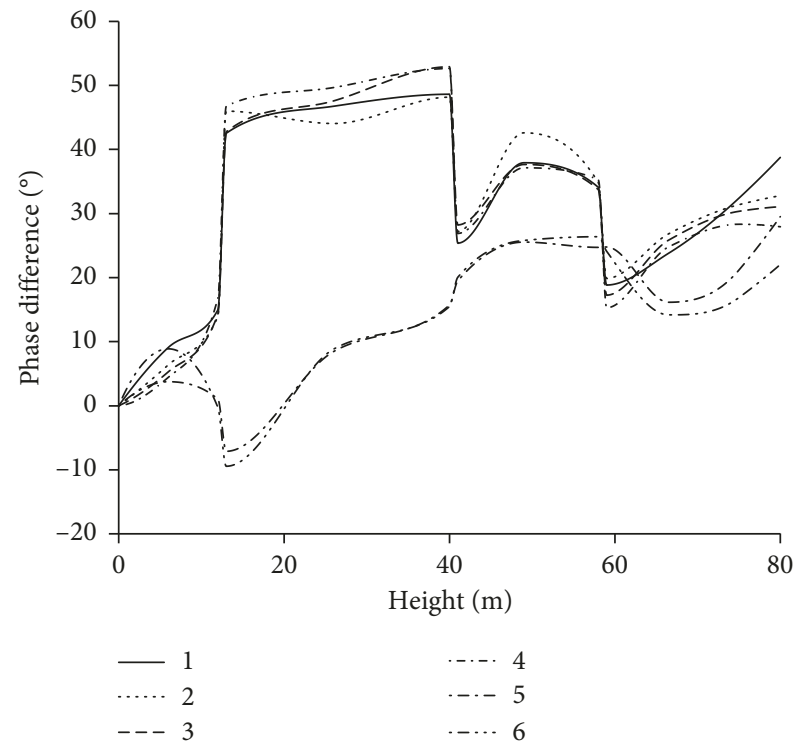

(b)

Figure 5: Vibration modes and phase differences of the No. 2 wind turbine tower. (a) The first-order vibration mode under six working conditions. (b) The first-order phase difference under six working conditions.

upper and lower plates. After the bolts were retightened, the phase difference curves measured under conditions 5 to 6 were relatively stable compared to the phase difference curves before the bolts were retightened. Indeed, there was no significant increase or decrease between the measuring points near the upper and lower plates of the flange of the upper bolt. Therefore, by analyzing the first-order phase difference curve of the six wind turbine towers before and after the retightening of the bolts, it is shown that even if the flange bolt looseness ratio is low, for example, $6 \%$, it can still cause a significant change of phase between the upper and lower flange plates. This fully demonstrates that the firstorder phase difference curves of the wind turbine towers are very sensitive to the bolt looseness of the flanges.

The flanges of the six wind turbine towers have different looseness degrees. By comparing the vibration characteristics before and after bolt, the variation characteristics of their natural frequencies, damping ratios, first-order vibration modes, and first-order phase differences were obtained, which are shown in Table 6. 


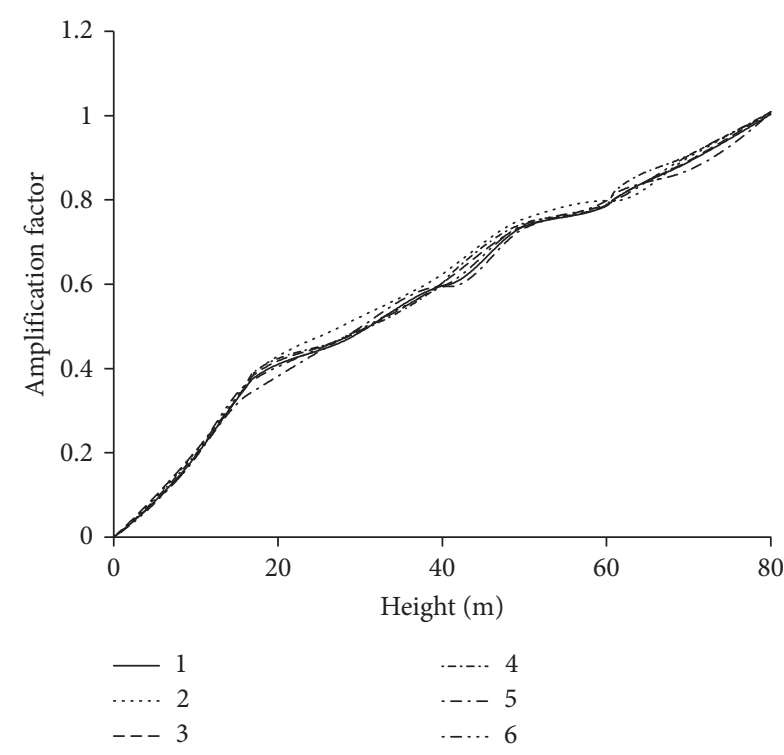

(a)

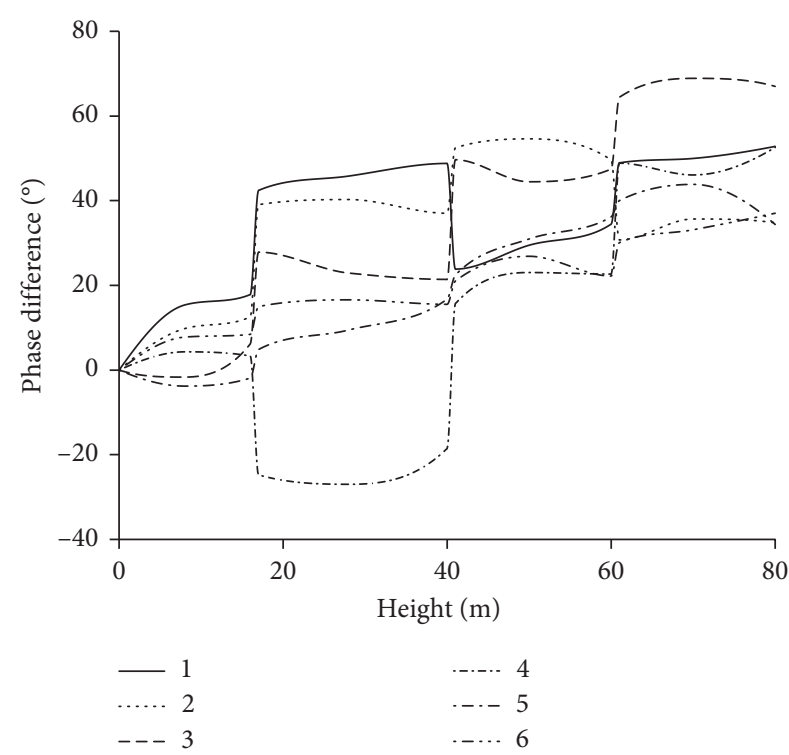

(b)

Figure 6: Vibration modes and phase differences of the No. 3 wind turbine tower. (a) The first-order vibration mode under six working conditions. (b) The first-order phase difference under six working conditions.

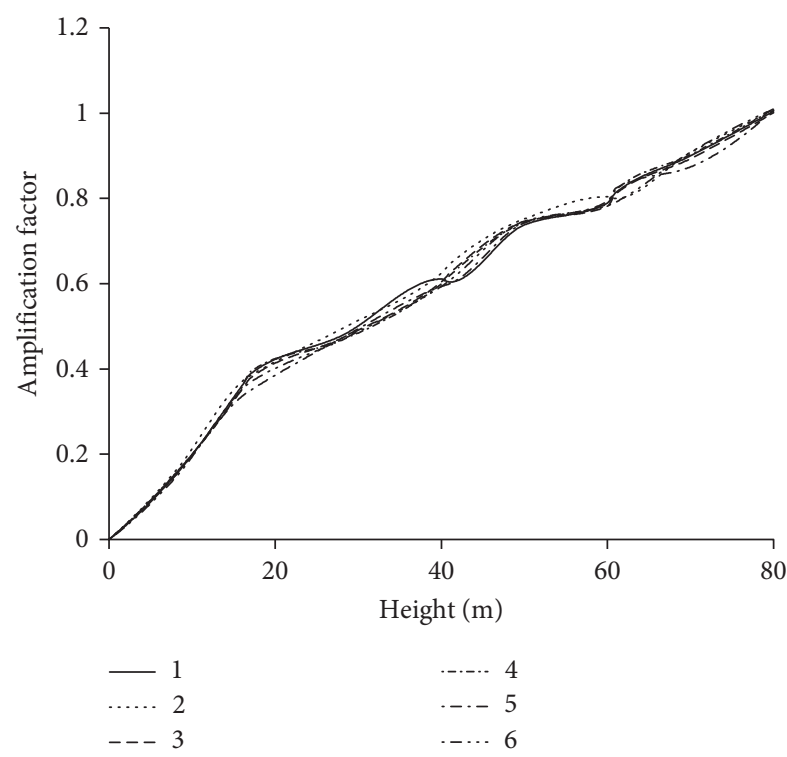

(a)

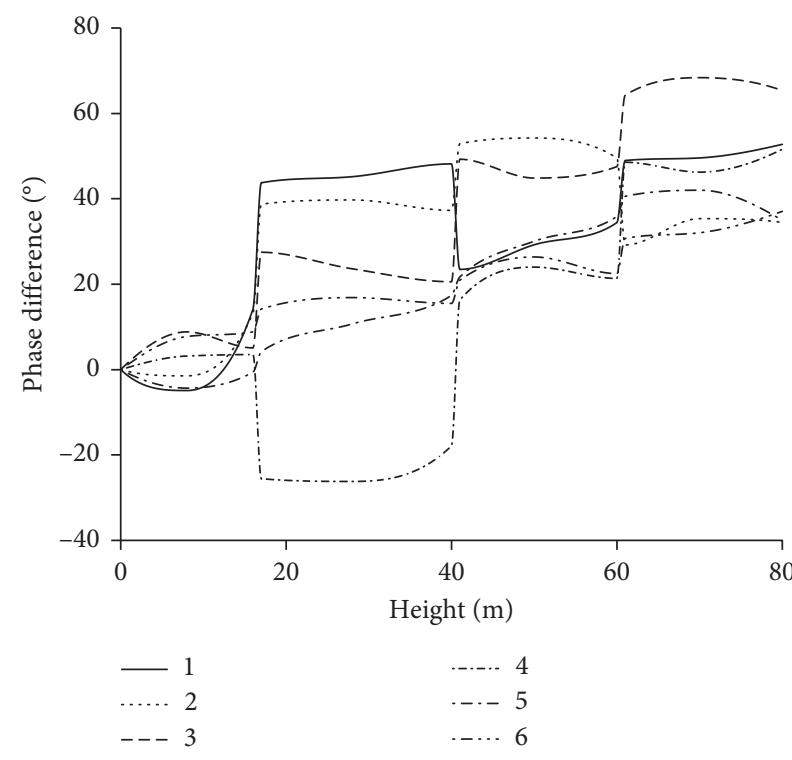

(b)

Figure 7: Vibration modes and phase differences of the No. 4 wind turbine tower. (a) The first-order vibration mode under six working conditions. (b) The first-order phase difference under six working conditions.

\section{Conclusions}

Bolts are important components of wind turbine towers, which are used to connect every section of the towers. However, bolt looseness is prone to occur due to long-term vibrations, which directly cause wind turbine towers to collapse in severe cases. Therefore, bolt looseness is one of the most common deficiencies in wind turbine towers and the main object of daily maintenance. In this paper, detailed vibration tests and analyses were carried out before and after maintenance on six wind turbine towers with loose bolts. It is concluded that the following relationship exists between the vibration characteristics and the bolt looseness of the wind turbine towers:

(1) The first-order natural frequency of wind turbine towers is generally lower than $0.5 \mathrm{~Hz}$, and the main vibration energy is concentrated at this frequency point. However, the first-order frequency is not sensitive to the bolt looseness of the flanges; for 


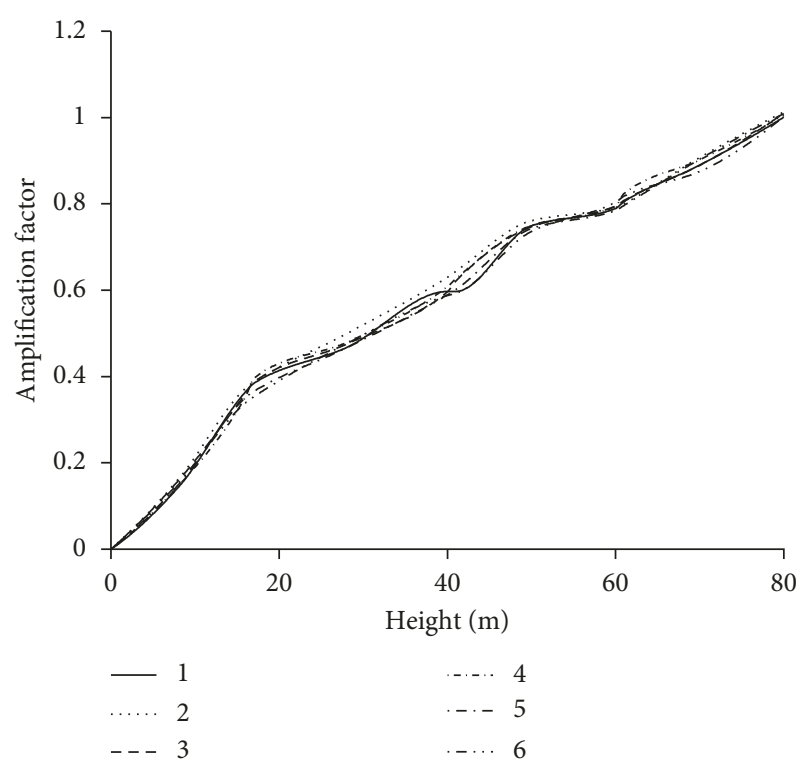

(a)

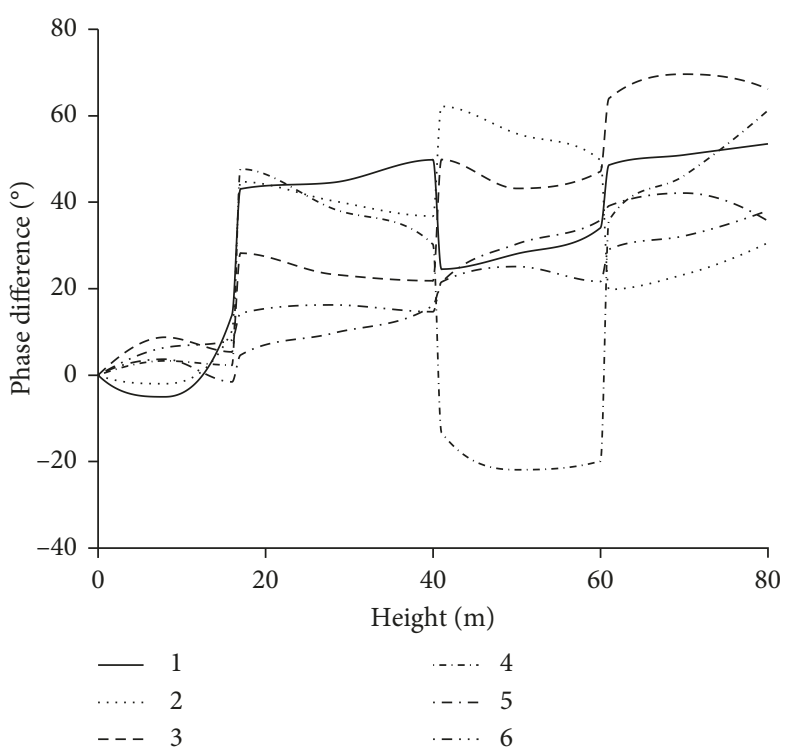

(b)

Figure 8: Vibration modes and phase differences of the No. 5 wind turbine tower. (a) The first-order vibration mode under six working conditions. (b) The first-order phase difference under six working conditions.

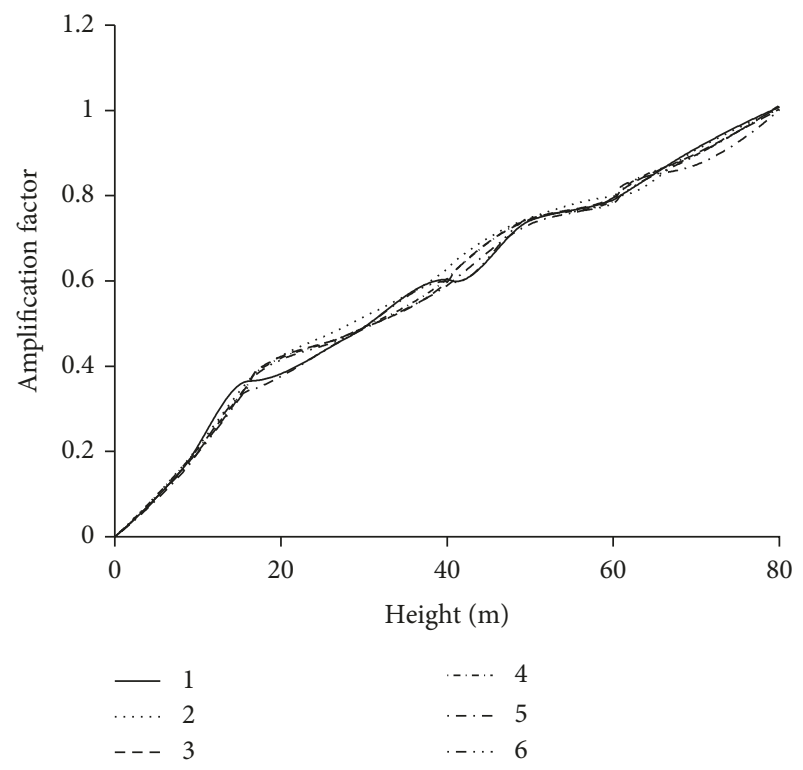

(a)

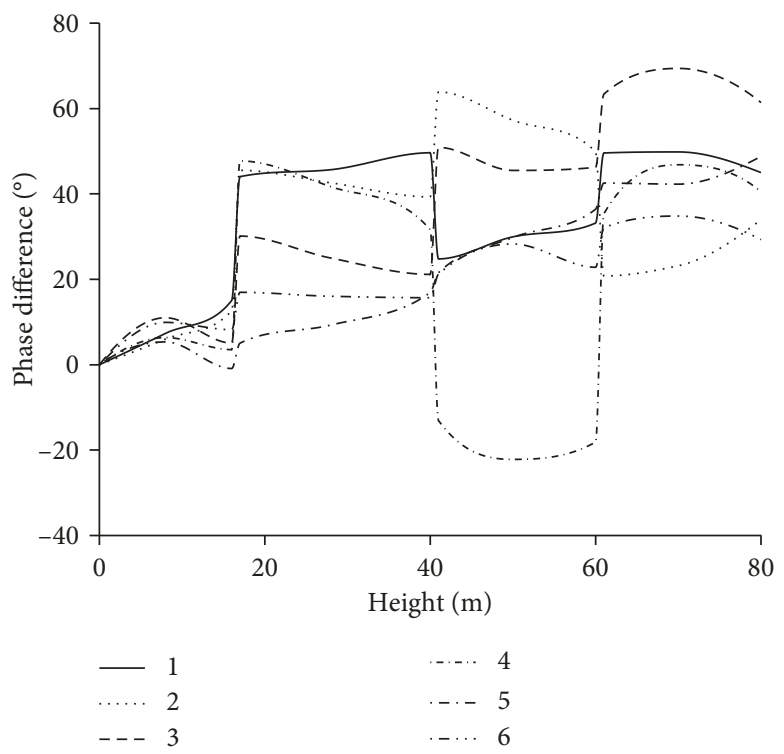

(b)

Figure 9: Vibration modes and phase differences of the No. 6 wind turbine tower. (a) The first-order vibration mode under six working conditions. (b) The first-order phase difference under six working conditions.

example, the bolt looseness ratio of a certain flange reached $64 \%$, but the first-order natural frequency was exactly the same as the value measured after bolt retightening.

(2) The damping ratio corresponds to the first-order natural frequency of wind turbine tower changes before and after the flange bolt retightening, but the change (before and after) is small. For example, the looseness ratio of the first flange bolt of the No. 5 wind turbine tower was $64 \%$, and the bolt looseness ratios on the other two flanges were as high as $24 \%$ and $15 \%$, respectively, but the observed change was only $10 \%$ compared to the damping ratio after the bolts were retightened.

(3) Although all six wind turbine towers had high bolt looseness ratios, the first-order mode curve did not change much compared with the first-order mode curve after bolt retightening. 
TABLE 6: Vibration characteristics before and after bolt tightening of the six wind turbine towers.

\begin{tabular}{|c|c|c|c|c|}
\hline $\begin{array}{l}\text { Tower } \\
\text { ID }\end{array}$ & $\begin{array}{l}\text { Comparison of first-order } \\
\text { natural frequency before and } \\
\text { after the bolt retightening }\end{array}$ & $\begin{array}{l}\text { Comparison of first-order } \\
\text { damping ratio before and after } \\
\text { the bolt retightening }\end{array}$ & $\begin{array}{l}\text { Comparison of first-order } \\
\text { vibration mode before and } \\
\text { after the bolt retightening }\end{array}$ & $\begin{array}{l}\text { Comparison of first-order } \\
\text { phase difference before and } \\
\text { after the bolt retightening }\end{array}$ \\
\hline 1 & No change & Difference is less than $2 \%$ & Similar & $\begin{array}{l}\text { There is a sudden change in the } \\
\text { phase difference between the } \\
\text { upper and lower plates before } \\
\text { tightening, and the sudden } \\
\text { change disappears after } \\
\text { tightening }\end{array}$ \\
\hline
\end{tabular}

$2 \quad$ No change Difference is less than $2 \% \quad$ Similar phase difference between the upper and lower plates before tightening, and the sudden change disappears after tightening

There is a sudden change in the phase difference between the

3

No change

Difference is less than $2 \%$

Similar upper and lower plates before tightening, and the sudden change disappears after tightening

There is a sudden change in the phase difference between the

$4 \quad$ No change Difference is less than $2 \% \quad$ Similar upper and lower plates before tightening, and the sudden change disappears after tightening

There is a sudden change in the phase difference between the 5 No change Difference is near $10 \%$ Similar upper and lower plates before tightening, and the sudden change disappears after tightening

There is a sudden change in the phase difference between the $6 \quad$ No change Difference is less than $2 \% \quad$ Similar upper and lower plates before tightening, and the sudden change disappears after tightening

(4) The absolute value of the phase difference between the upper and lower plates of a flange with a certain bolt looseness ratio will increase significantly compared with the absolute value after the bolts are retightened. For example, although the bolt looseness ratio of one flange was found to be only $6 \%$, the absolute value of the phase difference between the upper and lower plates significantly increased after the bolts were tightened.

According to the above points, the natural frequency, damping ratio, vibration mode, and other vibration characteristics of a wind turbine tower are insensitive to the bolt looseness degree of the flanges. However, the absolute value of the phase difference between the upper and lower plates of the wind turbine tower flanges is very sensitive to the bolt looseness degree of the flange. Thus, the looseness of a flange bolt can be identified based on the vibration characteristics of the wind turbine tower via a change in the measured phase difference. Therefore, the results presented in this paper provide reference values for the rapid detection of flange bolt looseness and realtime monitoring of operational safety of wind turbine towers.

\section{Data Availability}

The data used to support the findings of this study are included within the article and can be used for other researches.

\section{Conflicts of Interest}

The authors declare that they have no conflicts of interest.

\section{Acknowledgments}

This study was supported by the project "Research on common damage monitoring and evaluation methods for 
wind turbine towers" of the Institute of Engineering $\mathrm{Me}$ chanics of China Earthquake Administration (no. 2017B02).

\section{References}

[1] T. Wei, K. Wu, and J.-W. Huang, "Prevent loosing detection technology of the wind turbines tower bolts," Machinery \& Electronics, vol. 8, pp. 78-80, 2013.

[2] Global Wind Energy Council, "Global wind report-annual market update 2014," Global Wind Energy Council, Belgium, 2015.

[3] B.-L. Li and X.-G. Song, Structural Dynamics of Wind Turbines, Beihang University Press, Beijing, China, 2009.

[4] F. Marquez, A. Tobias, J. Perez, and M. Papaelias, "Condition monitoring of wind turbines: techniques and methods," Renew Energy, vol. 46, pp. 169-178, 2012.

[5] Y.-M. Gong and C.-S. Wu, "Development of testing and measuring system for high strength bolt," Journal of Shanghai University of Engineering Science, vol. 25, pp. 27-30, 2011.

[6] F. Magalhães, Á. Cunha, E. Caetano, and R. Brincker, "Damping estimation using free decays and ambient vibration tests," Mechanical Systems and Signal Processing, vol. 24, no. 5, pp. 1274-1290, 2010.

[7] G. Oliveira, F. Magalhães, Á. Cunha, and E. Caetano, "Continuous dynamic monitoring of an onshore wind turbine," Engineering Structures, vol. 164, pp. 22-39, 2018.

[8] B.-Y. Gou, Q.-H. Lu, B. Wang, and S.-Y Wang, "Bolt tightening force detection using outlier analysis of structural natural frequencies," Journal of Vibration and Shock, vol. 34, no. 23, pp. 77-82, 2015.

[9] J. Yu, S.-S. Xie, L.-T. Ren, Z.-Y. Zhang, L. Wang, and L.-G. Wang, "Fractal research on the assembly vibration detection of rod fastening rotor," Journal of Vibration and Shock, vol. 33, no. 14, pp. 84-88, 2014.

[10] H. Zuo, K. Bi, and H. Hao, "Dynamic analyses of operating offshore wind turbines including soil-structure interaction," Engineering Structures, vol. 157, pp. 42-62, 2018.

[11] H. Zuo, K. Bi, and H. Hao, "Using multiple tuned mass dampers to control offshore wind turbine vibrations under multiple hazards," Engineering Structures, vol. 141, pp. 303315, 2017.

[12] J. Chen and C. T. Georgakis, "Tuned rolling-ball dampers for vibration control in wind turbines," Journal of Sound and Vibration, vol. 332, no. 21, pp. 5271-5282, 2013.

[13] M. Damgaard, V. Zania, L. V. Andersen, and L. B. Ibsen, "Effects of soil-structure interaction on real time dynamic response of offshore wind turbines on monopiles," Engineering Structures, vol. 75, pp. 388-401, 2014.

[14] Y.-G. Li, X.-N. Kong, and Y.-Y. Gao, "Method for detecting bolt looseness based on probability density of vibration signals of two connected parts and principal component analysis," Journal of Vibration and Shock, vol. 34, no. 1, pp. 63-67, 2015.

[15] Y. Yuan, Y. Zeng, and C.-L. Chen, "Comparison with the vibration characteristics of the different wind turbine towers," Dongfang Electrical Machine, no. 5, pp. 43-46, 2012.

[16] R. Younsi, I. El-Batanony, J.-B. Tritsch, H. Naji, and B. Landjerit, "Dynamic study of a wind turbine blade with horizontal axis," European Journal of Mechanics-A/Solids, vol. 20, no. 2, pp. 241-252, 2001.

[17] P. J. Murtagh, B. Basu, and B. M. Broderick, "Mode acceleration approach for rotating wind turbine blades," Journal of Multi-Body Dynamics, vol. 218, no. 3, pp. 159-167, 2004.

[18] P. J. Murtagh, B. Basu, and B. M. Broderick, "Along-wind response of a wind turbine tower with blade coupling subjected to rotationally sampled wind loading," Engineering Structures, vol. 27, no. 8, pp. 1209-1219, 2005.

[19] Y.-X. Liu, Structure Dynamic Analysis and Buckling Stability Analysis on Large Wind Turbine Tower, Lanzhou University of Technology, Lanzhou, China, 2012.

[20] W.-X. Ren and G. De Roeck, "Structural damage identification using modal data. I: simulation verification," Journal of Structural Engineering, vol. 128, no. 1, pp. 87-95, 2002.

[21] W.-X. Ren and G. De Roeck, "Structural damage identification using modal data. II: test verification," Journal of Structural Engineering, vol. 128, no. 1, pp. 96-104, 2002.

[22] Z. Zhu and L. Hu, "The research of torque method and torgue/ rotation method," Design \& Manufacture of Diesel Engine, vol. 2, no. 14, pp. 39-42, 2005.

[23] F. Santangelo, G. Failla, F. Arena, and C. Ruzzo, "On timedomain uncoupled analyses for offshore wind turbines under seismic loads," Bulletin of Earthquake Engineering, vol. 16, no. 2, pp. 1007-1040, 2018. 


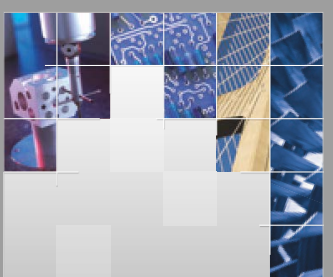

\section{Enfincering}
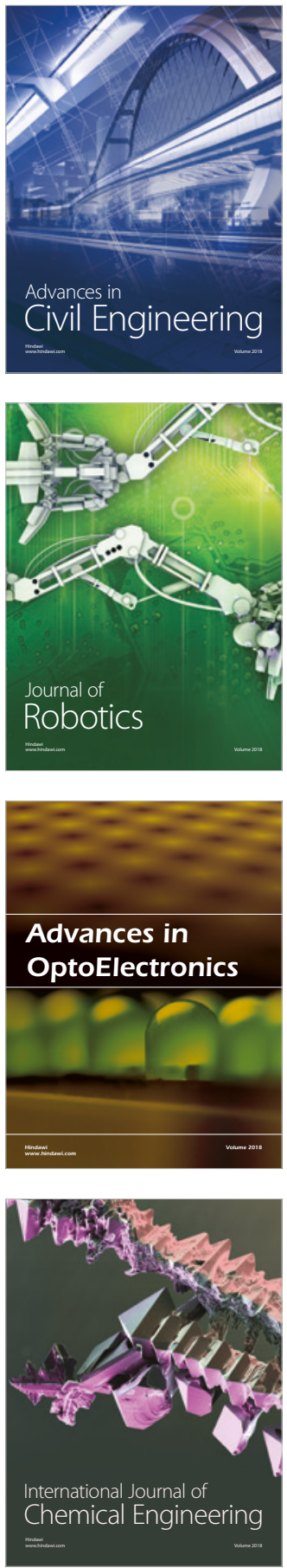

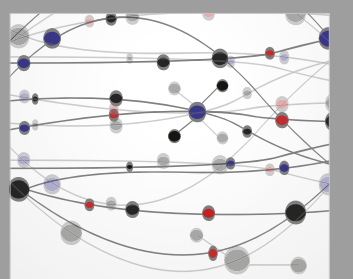

\section{Rotating \\ Machinery}

The Scientific World Journal

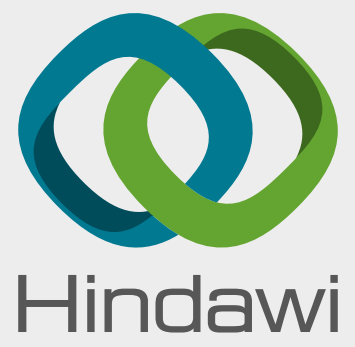

Submit your manuscripts at

www.hindawi.com
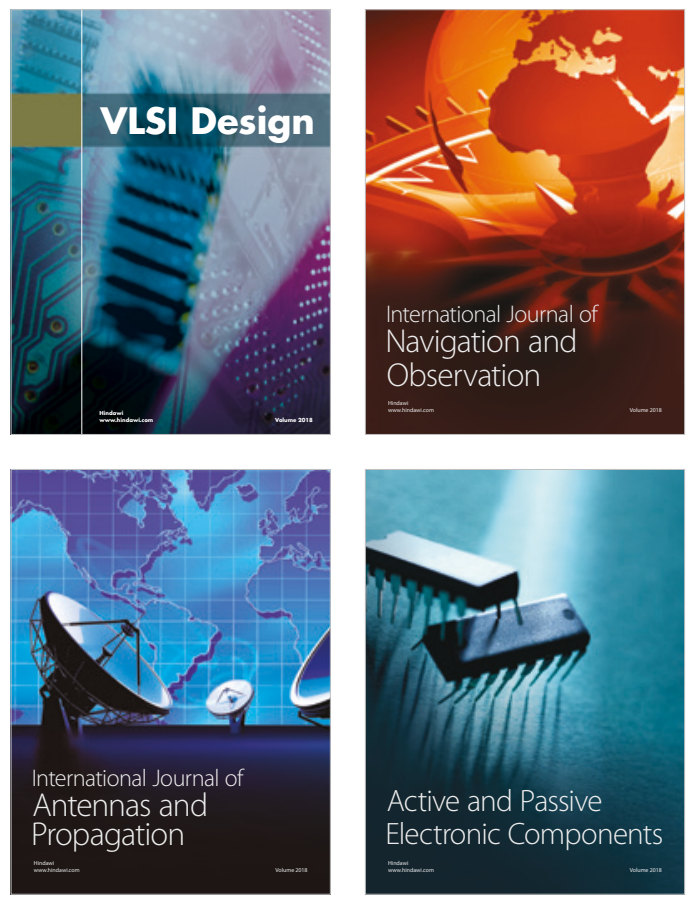
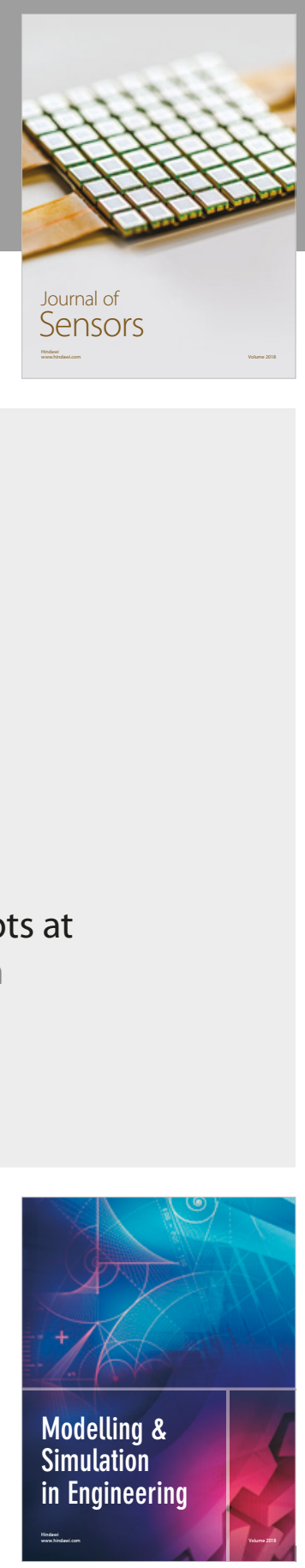

\section{Advances \\ Multimedia}
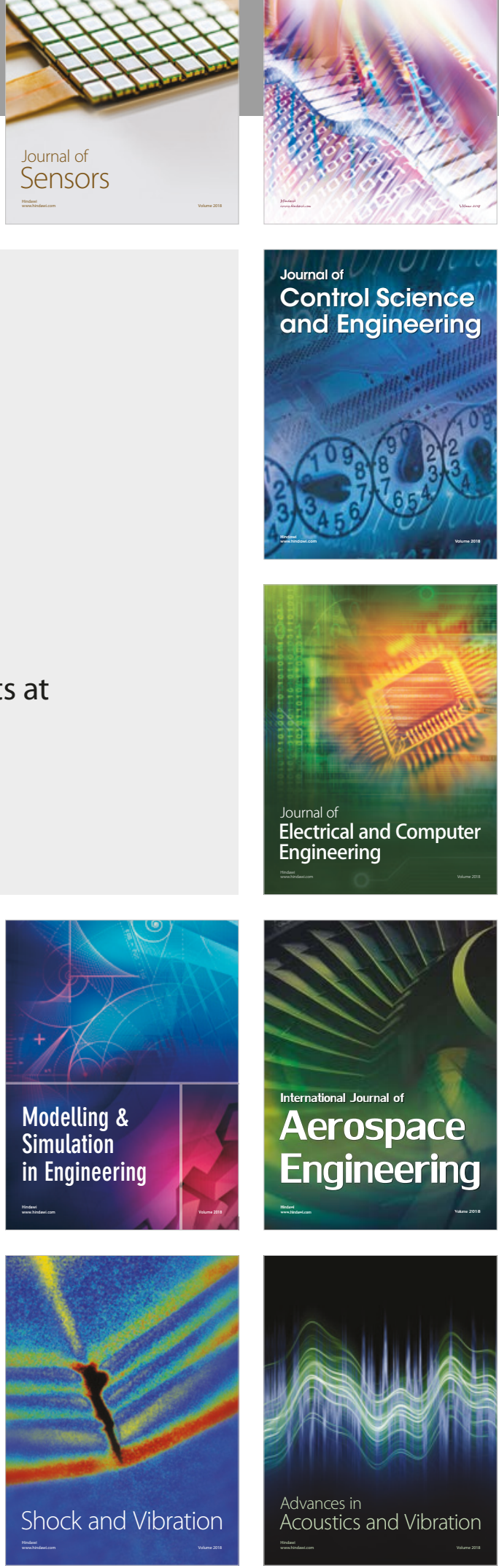